\title{
Association Between Cortisol and Left Ventricular Diastolic Dysfunction in Patients With Diabetes Mellitus: A Case Control Study
}

\section{RIKAKO SAGARA}

Kyushu University: Kyushu Daigaku https://orcid.org/0000-0003-2908-5522

Tomoaki Inoue ( $\nabla$ tomo-i@intmed3.med.kyushu-u.ac.jp)

Kyushu University https://orcid.org/0000-0002-3829-3908

\section{Noriyuki Sonoda}

Kyushu University: Kyushu Daigaku

\section{Chieko Yano}

Kyushu University: Kyushu Daigaku

\section{Misato Motoya}

Kyushu University: Kyushu Daigaku

Hironobu Umakoshi

Kyushu University: Kyushu Daigaku

\section{Ryuichi Sakamoto}

Kyushu University: Kyushu Daigaku

Yoshihiro Ogawa

Kyushu University: Kyushu Daigaku

Original investigation

Keywords: cortisol, cardiac dysfunction, diabetes

Posted Date: April 20th, 2021

DOI: https://doi.org/10.21203/rs.3.rs-415041/v1

License: (1) (1) This work is licensed under a Creative Commons Attribution 4.0 International License. Read Full License 


\section{Abstract}

\section{Introduction:}

Diabetes mellitus (DM) is a major risk factor for the development of cardiovascular diseases. Heart failure with preserved ejection fraction is characterized by left ventricular diastolic dysfunction (LVDD). It has been reported that excess cortisol found in patients with Cushing's syndrome was associated with the development of LVDD. However, the relationship between cortisol concentration and LVDD in patients with DM has not been addressed.

\section{Research Design and Methods:}

We enrolled 109 patients with DM and 104 patients without DM who had undergone echocardiographic examination at Kyushu University Hospital, Japan, between November 2016 and March 2019. Left ventricular function was evaluated and the ratio of early diastolic velocity from transmitral inflow to early diastolic velocity (E/e区) was used as an index of diastolic function. Plasma cortisol concentrations, glycemic control, lipid profiles, treatment with anti-diabetic drugs, and other clinical characteristics were evaluated, and their associations with $\mathrm{E} / \mathrm{e} \otimes$ were determined using univariate and multivariate analyses.

\section{Results}

Multivariate linear regression analysis showed that log $E / e \rrbracket$ was positively correlated with age $(p=$ $0.017)$, log systolic blood pressure $(p=0.004)$, and cortisol $(p=0.037)$ and negatively correlated with eGFR $(p=0.016)$ and the usage of SGLT2 inhibitors $(p=0.042)$ in patients with DM. Multivariate analysis showed that cortisol was positively correlated with age $(p=0.016)$ and HbA1c $(p=0.011)$. There was no association between $\mathrm{E} / \mathrm{e} \mathbb{\mathrm { V }}$ and cortisol in patients without $\mathrm{DM}$.

\section{Conclusions}

Increased cortisol levels may increase the risk of developing LVDD in DM patients.

\section{Background}

Diabetes mellitus (DM) is a major risk factor for the development of cardiovascular diseases. Heart failure with preserved ejection fraction (HFpEF), which is characterized by left ventricular diastolic dysfunction (LVDD), is clinically important in patients with DM. Indeed, the prevalence of DM is approximately $45 \%$ in patients with $\operatorname{HFpEF(1).~}$

Patients with normal left ventricular wall contraction may have symptoms of heart failure. Therefore, it is important to evaluate left ventricular diastolic function separately from left ventricular systolic 
function(2). Doppler echocardiography is widely used for the noninvasive assessment of diastolic filling of the left ventricle(3). Tissue Doppler imaging (TDI) of mitral annular motion has been proposed to correct for the influence of myocardial relaxation on transmitral flows and shown to be an excellent predictor of $\operatorname{LVDD}(3)$.

Cushing's syndrome, including Cushing's disease and adrenal Cushing's syndrome, is characterized by excess blood levels of cortisol and confers an approximately 4-fold increase in mortality compared with the general population(4). The increased mortality is due mainly to cardiovascular complications(5). It has been recognized that patients with Cushing's syndrome have a high incidence of left ventricular hypertrophy and dysfunction(6). Additionally, the incidence of cardiovascular outcomes in patients with subclinical Cushing's syndrome was more than three times greater than in patients with nonfunctioning adrenal adenoma(7)(8). It is likely that cortisol affects cardiac structure and function, although its relationship with LVDD in patients with DM has not been addressed. Therefore, we designed a crosssectional study to determine the relationship between cortisol and LVDD in patients with DM who did not have overt cardiovascular diseases.

\section{Methods}

Some of the methods used in this study were described previously(9).

\section{Subjects}

Between November 2016 and March 2019, we consecutively recruited 109 patients with DM and 104 patients without DM who had undergone echocardiographic examination at the metabolic ward of Kyushu University Hospital, Fukuoka, Japan. Patients were excluded if they 1) were taking steroids, 2) were undergoing hemodialysis treatment, or 3 ) had overt heart failure. Patients without DM consisted of those who were hospitalized for hypertension, gastrointestinal polyps, and/or adrenal mass whose diagnosis finally became nonfunctional. All of the patients underwent clinical evaluation, laboratory assessment, and echocardiographic examination. Blood concentrations of fasting plasma glucose, $\mathrm{HbA1c}$, total cholesterol, high-density lipoprotein cholesterol, triglycerides, uric acid, creatinine, estimated glomerular filtration rate (eGFR), ACTH, and cortisol (at 8:00 am, fasting) were measured. Serum cortisol concentrations were determined by electrochemiluminescence immunoassay (ECLusys Cortisol $\square$ Kits, Roche in Vitro Diagnostics, Tokyo, Japan). Clinical data and information regarding treatment of the patients with anti-diabetic drugs were obtained from medical records. HbA1c levels were determined using the criteria of the National Glycohemoglobin Standardization Program. The study protocol was approved by the Clinical Ethics Committee of Kyushu University Hospital (protocol \#29-645). This study was performed in accordance with the Declaration of Helsinki.

\section{Echocardiography}

All echocardiographic examinations were performed with an Aplio i900 TUS-Al900 imager (Canon Medical Systems, Inc., Tokyo, Japan). Chamber dimensions and left ventricular ejection fractions (LVEF) 
were measured in accordance with the recommendations of the American Society of

Echocardiography(10). The left ventricular mass index (LVMI) was calculated according to the Devereux formula and expressed as a ratio of the left ventricular mass to body surface area(10). The relative wall thickness (RWT) was based on the end-diastolic posterior wall thickness (PWTd) and the end-diastolic left ventricular dimension (LVDd). RWT was calculated as ( $2 \times$ PWTd)/LVDd. The following mitral pulse wave Doppler and tissue Doppler parameters were measured to assess diastolic function. Peak velocities of $E$ and $A$ waves of mitral inflow, the $E / A$ ratio, and deceleration time of the $E$ wave were measured from the mitral flow velocity pattern using pulse wave Doppler imaging. The peak early diastolic myocardial velocity ( $\mathrm{e} \Downarrow$ velocity) was measured using tissue Doppler imaging, and the ratio of $\mathrm{E}$ velocity to $\mathrm{e} \Downarrow$ velocity $(\mathrm{E} / \mathrm{e} \mathbb{Z})$ was calculated.

\section{Data Analysis}

All statistical analyses were performed using $\mathrm{JMP}^{\circledR}$ statistical software, version 14 (SAS Institute Inc.,

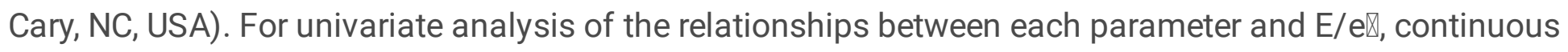
and categorical variables were analyzed using Spearman's rank-order correlation and the Mann-Whitney $U$ test, respectively. Variables that were significant in the univariate model were entered into a multivariate linear regression analysis. Gender and glucose-lowering therapy were coded as dummy variables. Continuous variables were logarithmically transformed if they were not normally distributed according to the Kolmogorov-Smirnov test. Categorical variables are presented as number (\%) or median (lower quartile-upper quartile). A p-value $<0.05$ was considered statistically significant.

\section{Results}

The clinical, anthropometric, and metabolic characteristics of the study participants are shown in Table 1. The DM group was older than the non-DM group, and there was no significant difference in the sex ratio between the 2 groups. Fasting plasma glucose, $\mathrm{HbA} 1 \mathrm{c}$, systolic blood pressure (SBP), and cortisol concentrations were significantly higher, and eGFR and high-density lipoprotein (HDL) cholesterol concentrations were significantly lower in the DM group than in the non-DM group. 
Table 1

Demographic and clinical characteristics of the 2 patient cohorts $(N=213)$

\begin{tabular}{|c|c|c|c|}
\hline Patient characteristics & Control $(N=104)$ & $\mathrm{DM}(\mathrm{N}=109)$ & $p$ value \\
\hline Age, years & $54(43-69)$ & $66(56-72)$ & $<0.001$ \\
\hline Sex, male/female, \% & $53(51.0) / 51(49.0)$ & $54(49.5) / 55(50.5)$ & 0.836 \\
\hline Body mass index, $\mathrm{kg} / \mathrm{m}^{2}$ & $23.7(21.3-26.1)$ & $25.5(21.3-29.9)$ & 0.147 \\
\hline Duration of diabetes, years & & $10(5-18)$ & \\
\hline SBP, mmHg & $119(112-129)$ & $126(111-141)$ & 0.038 \\
\hline DBP, mmHg & $70(65-79)$ & $75(68-84)$ & 0.107 \\
\hline Fasting plasma glucose, mg/dl & $91(84-98)$ & $143(119-183)$ & $<0.001$ \\
\hline $\mathrm{HbA} 1 \mathrm{c}, \%$ & $5.6(5.4-5.7)$ & $8.9(7.7-10.2)$ & $<0.001$ \\
\hline Total cholesterol, mg/dl & $187(161-211)$ & $176(151-202)$ & 0.099 \\
\hline $\mathrm{HDL}-\mathrm{C}, \mathrm{mg} / \mathrm{dl}$ & $51(43-63)$ & $45(37-54)$ & 0.003 \\
\hline $\mathrm{TG}, \mathrm{mg} / \mathrm{dl}$ & $109(80-146)$ & $123(85-181)$ & 0.062 \\
\hline $\mathrm{UA}, \mathrm{mg} / \mathrm{dl}$ & $5.5(4.2-6.4)$ & $5.7(4.6-6.7)$ & 0.222 \\
\hline Cre, mg/dl & $0.64(0.58-0.77)$ & $0.69(0.60-0.96)$ & 0.009 \\
\hline eGFR, mL/min/1.73m² & $83.5(70-98.5)$ & $72.5(57.0-87.0)$ & 0.001 \\
\hline ACTH, pg/ml & $31.1(20.9-44.9)$ & $36.0(21.6-52.6)$ & 0.186 \\
\hline Cortisol, $\mu \mathrm{g} / \mathrm{dl}$ & $10.35(7.4-14.0)$ & $12.1(10.0-15.2)$ & 0.003 \\
\hline \multicolumn{4}{|l|}{ Glucose-lowering therapies } \\
\hline Biguanide & & $46(42)$ & \\
\hline Sulfonylureas & & $27(25)$ & \\
\hline Dipeptidyl peptidase- 4 inhibitors & & $49(45)$ & \\
\hline Thiazolidinediones & & $4(4)$ & \\
\hline a-Glucosidase inhibitor & & $13(12)$ & \\
\hline Glinide & & $8(7)$ & \\
\hline
\end{tabular}

Categorical variables are presented as number (\%) or median (lower quartile-upper quartile).

Abbreviations: DM, diabetes mellitus; SBP, systolic blood pressure; DBP, diastolic blood pressure; $\mathrm{HbA1c}$, hemoglobin A1c; HDL-C, high-density lipoprotein cholesterol; TG, triglycerides; UA, uric acid; Cre, creatinine; eGFR, estimate glomerular filtration rate; ACTH, adrenocorticotropic hormone 


\begin{tabular}{|lll|}
\hline Patient characteristics & Control $(\mathbf{N}=104)$ & DM $(\mathbf{N}=109)$ \\
\hline Glucagon-like peptide-1 agonists & $20(18)$ \\
\hline Sodium glucose cotransporter 2 inhibitor & $21(20)$ \\
\hline Insulin & $36(33)$ \\
\hline Categorical variables are presented as number (\%) or median (lower quartile-upper quartile). \\
\hline $\begin{array}{l}\text { Abbreviations: DM, diabetes mellitus; SBP, systolic blood pressure; DBP, diastolic blood pressure; } \\
\text { HbA1c, hemoglobin A1c; HDL-C, high-density lipoprotein cholesterol; TG, triglycerides; UA, uric acid; } \\
\text { Cre, creatinine; eGFR, estimate glomerular filtration rate; ACTH, adrenocorticotropic hormone }\end{array}$ \\
\hline
\end{tabular}

The echocardiographic data is shown in Table 2. LVEF was preserved in both the DM and non-DM groups [69\% (IQR 64-73\%) vs. 70\% (IQR 66-73\%), $p=0.141]$. However, the DM group had a significantly higher E/e冈 ratio compared with the non-DM group [10.4 (IQR 8.2-13.3) vs. 8.3 (IQR 6.3-10.1), p<0.001], suggesting diastolic dysfunction in the patients with DM. The LVMI and RWT were significantly higher in the DM group than in the non-DM group [83g/m² (IQR 74-104) vs $79 \mathrm{~g} / \mathrm{m}^{2}$ (IQR 64-95), p<0.003]. 
Table 2

Echocardiographic data from each patient cohort $(\mathrm{N}=213)$

\begin{tabular}{|c|c|c|c|}
\hline Echocardiograph findings & Control $(\mathrm{N}=104)$ & $\mathrm{DM}(\mathrm{N}=109)$ & $p$ value \\
\hline $\mathrm{LAD}, \mathrm{mm}$ & $33(30-37)$ & $35(30-40)$ & 0.023 \\
\hline LVDd, mm & $46(43-49)$ & $45(42-49)$ & 0.636 \\
\hline LVDs, mm & $28(25-30)$ & $28(25-31)$ & 0.690 \\
\hline IVSd, mm & $8(7-10)$ & $9(8-11)$ & $<0.001$ \\
\hline PWd, mm & $9(8-10)$ & $9(9-10)$ & $<0.001$ \\
\hline LVMI, g/m² & $79(64-95)$ & $83(74-104)$ & 0.003 \\
\hline RWT & $0.38(0.34-0.44)$ & $0.40(0.37-0.46)$ & $<0.001$ \\
\hline LVEF, \% & $70(66-73)$ & $69(64-73)$ & 0.141 \\
\hline E wave, $\mathrm{cm} / \mathrm{sec}$ & $67(57-77)$ & $65(54-79)$ & 0.657 \\
\hline A wave, $\mathrm{cm} / \mathrm{sec}$ & $63(54-80)$ & $78(64-92)$ & $<0.001$ \\
\hline $\mathrm{E} / \mathrm{A}$ & $1.0(0.8-1.3)$ & $0.8(0.6-1.0)$ & $<0.001$ \\
\hline DcT (ms) & $193(169-222)$ & $203(169-245)$ & 0.202 \\
\hline$e^{\prime}$ & $8.0(6.1-10.6)$ & $6.1(4.9-7.8)$ & $<0.001$ \\
\hline$E / e^{\prime}$ & $8.3(6.3-10.1)$ & $10.4(8.2-13.3)$ & $<0.001$ \\
\hline \multicolumn{4}{|c|}{ Categorical variables are presented as number (\%) or median (lower quartile-upper quartile). } \\
\hline \multicolumn{4}{|c|}{$\begin{array}{l}\text { Abbreviations: DM, diabetes mellitus; LAD, left atrial dimension; LVDd, left ventricular end-diastolic } \\
\text { dimension; LVDs, left ventricular end-systolic dimension; IVSd, interventricular septal wall dimension; } \\
\text { PWd, posterior wall thickness dimension; LVMI, left ventricular mass index; RWT, relative wall } \\
\text { thickness; LVEF, left ventricular ejection fraction; Dct, deceleration time of mitral E wave. }\end{array}$} \\
\hline
\end{tabular}

Because the $\mathrm{E} / \mathrm{e} \mathbb{\text { ratio }}$ and plasma cortisol concentrations were higher in the DM group than in non-DM group, we evaluated the relationships between the $\mathrm{E} / \mathrm{e} \mathbb{\mathrm { r }}$ ratio and other variables, including cortisol (Table 3$)$. In this analysis, age ( $<<0.001)$, duration of diabetes $(p=0.039)$, SBP $(p<0.001)$, and cortisol ( $p$

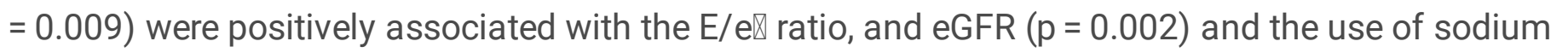
glucose cotransporter 2 (SGLT2) inhibitors $(p<0.001)$ were inversely associated with the E/e $\mathbb{\text { ratio. There }}$

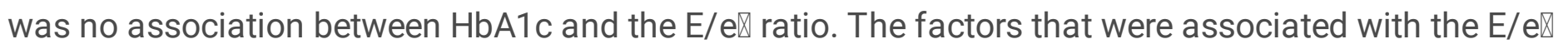
ratio in the univariate analysis were included in a multivariate linear regression model. The parameters that were independently associated with the E/e区 ratio in the DM group are shown in Table 4. The log of the $E / e \rrbracket$ ratio was positively correlated with age $(p=0.017)$, the log of SBP $(p=0.004)$, and cortisol $(p=$ $0.037)$ and negatively correlated with eGFR and the use of SGLT2 inhibitors $(p=0.042)$. 
Table 3

Correlations between $\mathrm{E} / \mathrm{e} \mathbb{\mathrm { a }}$ and other variables in the $\mathrm{DM}$ patients

\begin{tabular}{|lll|}
\hline Variables & $\rho$ & $p$ value \\
\hline Age, years & 0.358 & $<0.001$ \\
\hline Sex, male/female, \% & 0.132 & 0.171 \\
\hline Body mass index, kg/m² & 0.074 & 0.445 \\
\hline Duration of diabetes, years & 0.199 & 0.039 \\
\hline SBP, mmHg & 0.306 & $<0.001$ \\
\hline DBP, mmHg & 0.059 & 0.544 \\
\hline Fasting plasma glucose, mg/dl & 0.150 & 0.120 \\
\hline HbA1c, \% & 0.057 & 0.573 \\
\hline Total cholesterol, mg/dl & 0.012 & 0.900 \\
\hline HDL-C, mg/dl & 0.025 & 0.796 \\
\hline TG, mg/dl & 0.078 & 0.420 \\
\hline UA, mg/dl & 0.095 & 0.325 \\
\hline Cre, mg/dl & 0.115 & 0.233 \\
\hline eGFR, mL/min/1.73m² & -0.289 & 0.002 \\
\hline ACTH, pg/ml & 0.058 & 0.549 \\
\hline Cortisol, $\mu$ g/dl & 0.248 & 0.009 \\
\hline Glucose-lowering therapies & 0.060 & \\
\hline Biguanide & -0.072 & 0.459 \\
\hline Sulfonylureas & 0.037 \\
\hline Dipeptidyl peptidase-4 inhibitors & 0.026 & 0.755 \\
\hline Thiazolidinediones & & 0.479 \\
\hline a-Glucosidase inhibitor & 0.069 \\
\hline
\end{tabular}

$p$ values were calculated using Spearman's rank correlation test or the Mann-Whitney $\mathrm{U}$ test, as appropriate.

Abbreviations: DM, diabetes mellitus; $E$, early diastolic filling velocity; e区, mitral annular early diastolic velocity; SBP, systolic blood pressure; DBP, diastolic blood pressure; HbA1c, hemoglobin A1 c; HDL-C, high-density lipoprotein cholesterol; TG, triglycerides; UA, uric acid; Cre, creatinine; eGFR, estimate glomerular filtration rate; $\mathrm{ACTH}$, adrenocorticotropic hormone. 


\begin{tabular}{|llc|}
\hline Variables & $\boldsymbol{\rho}$ & $\boldsymbol{p}$ value \\
\hline Glinide & -0.058 & 0.552 \\
\hline Glucagon-like peptide-1 agonists & 0.061 & 0.526 \\
\hline Sodium glucose cotransporter 2 inhibitor & -0.312 & $<0.001$ \\
\hline Insulin & -0.004 & 0.967 \\
\hline $\begin{array}{l}p \text { values were calculated using Spearman's rank correlation test or the Mann-Whitney U test, as } \\
\text { appropriate. }\end{array}$ & \\
\hline $\begin{array}{l}\text { Abbreviations: DM, diabetes mellitus; E, early diastolic filling velocity; e区, mitral annular early diastolic } \\
\text { velocity; SBP, systolic blood pressure; DBP, diastolic blood pressure; HbA1c, hemoglobin A1c; HDL-C, } \\
\text { high-density lipoprotein cholesterol; TG, triglycerides; UA, uric acid; Cre, creatinine; eGFR, estimate } \\
\text { glomerular filtration rate; ACTH, adrenocorticotropic hormone. }\end{array}$ \\
\hline
\end{tabular}

Table 4

Multivariate linear regression analysis of factors associated with $\log \mathrm{E} / \mathrm{e} \bigotimes$ in the $\mathrm{DM}$ patients

\begin{tabular}{|lll|}
\hline Variables & $\boldsymbol{\beta}$ & $\boldsymbol{p}$ value \\
\hline Age & 0.22 & 0.017 \\
\hline Duration of diabetes & 0.06 & 0.515 \\
\hline Log SBP & 0.25 & 0.004 \\
\hline eGFR & -0.21 & 0.016 \\
\hline Cortisol & 0.18 & 0.037 \\
\hline Use of SGLT2 inhibitor & -0.18 & 0.042 \\
\hline $\begin{array}{l}\text { Abbreviation: DM, diabetes mellitus; E, early diastolic filling velocity; e区, mitral annular early diastolic } \\
\text { velocity; SBP, systolic blood pressure; eGFR, estimate glomerular filtration rate; SGLT2, sodium } \\
\text { glucose cotransporter 2. }\end{array}$ & \\
\hline
\end{tabular}

We examined the factors that were associated with plasma cortisol concentrations in the diabetic state. Univariate analysis showed that age $(p=0.021)$, fasting plasma glucose $(p=0.003), \operatorname{HbA} 1 c(p=0.008)$, and HDL cholesterol $(p=0.010)$ were positively associated with cortisol, and uric acid $(p=0.039)$ was negatively associated with cortisol (Table S1). Multivariate linear regression analysis showed that cortisol was positively and independently correlated with the log of HbA1c $(p=0.011)$ and age $(p=0.016)$ (Table S2). These findings suggest that an elevated cortisol concentration in the blood is associated with diastolic dysfunction in patients with DM. In contrast, there was no correlation between E/e区 and cortisol in the non-DM group (Table S3).

\section{Discussion}




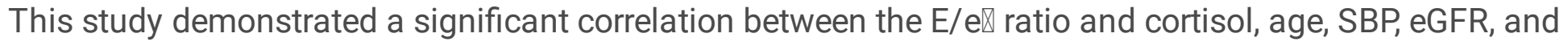
usage of SGLT2 inhibitors in patients with DM. It has been reported that the E/e区 ratio is linearly associated with invasively measured LV filling pressures(11)(3). Therefore, the E/e》 ratio may serve as a surrogate measure of diastolic function.

The key findings of this study were that cortisol concentrations were significantly higher in the DM group than in the non-DM group, and cortisol levels were independently and positively associated with the E/e区 ratio in patients with $\mathrm{DM}$. There was no significant correlation between $\mathrm{E} / \mathrm{e} \mathbb{V}$ and cortisol concentrations in patients without DM. A previous study reported that DM patients with microangiopathy and macroangiopathy had higher blood cortisol concentrations than DM patients without diabetic complications and non-DM patients.(12). It is conceivable that pathological excess of cortisol, such as that found in Cushing's syndrome, and mild cortisol excess found in DM plays a critical role in the development of cardiomyopathy.

Glucocorticoid receptors are abundantly expressed in the heart(13)(14). Therefore, cortisol may have direct effects on myocardial tissue. Indeed, in an animal study using several rodent models, glucocorticoids played an important role in the development of cardiac hypertrophy and progression to heart failure(15). Additionally, the mineralocorticoid receptor (MR) is present in cardiac tissue and has high affinity for both mineralocorticoids and glucocorticoids(16). Since glucocorticoids typically circulate at levels 100-fold higher than mineralocorticoids, the MR is likely to be constitutively occupied by glucocorticoids(16). In mineralocorticoid target tissues, the enzyme 11ß-hydroxysteroid dehydrogenase type 2 (11 $\beta$-HSD2) inactivates cortisol, which protects the MR from binding to glucocorticoids. Unlike other MR target tissues, there is no appreciable dehydrogenase activity in the heart, and glucocorticoids are free to activate the MR(16). Animal studies have shown that activation of the MR induces ventricular remodeling, hypertrophy, and fibrotic changes in the heart(17)(18) Furthermore, high concentrations of glucose stimulate protein kinase $C \beta$ signaling, which leads to MR stabilization and induction of its transcriptional activities(19). Taken together, cortisol may be involved in the development of diastolic dysfunction via activation of the MR in patients with DM. In this study, multivariate linear regression analysis showed that cortisol was positively correlated with $\mathrm{HbA1c}$ and age in the DM group. Patients with poor glycemic control and older patients with diabetes have higher cortisol concentrations, which may lead to the development of LVDD.

The data from this study are consistent with previous reports that the prevalence of LVDD is associated with age, blood pressure, eGFR(20)(21)(22)(23). Recent studies have shown that the SGLT2 inhibitors empagliflozin and canagliflozin significantly reduced cardiovascular-mediated death, overall mortality, and hospitalization for heart failure in patients with type 2 DM (T2DM)(23)(24)(25). Additionally, another study reported that canagliflozin improved LVDD(26), which is consistent with the association between LVDD and SGLT2 inhibitors found in this study. Taken together, these observations suggest that SGLT2 inhibitors may protect against the development of HFpEF, which is characterized by LVDD, in patients with T2DM. 
This study had several limitations. First, our study design was cross-sectional, and, therefore, cause-andeffect relationships could not be determined. Second, we did not collect 24-hour urine samples to measure cortisol, and cortisol measurements in blood may have been affected by diurnal fluctuations. Third, the number of study participants was relatively small. Future studies with larger cohorts will be required to validate the correlations that were observed in our study.

\section{Conclusions}

This study is the first demonstration of a positive correlation between cortisol and diastolic dysfunction in patients with DM. This study facilitates a greater understanding of the pathogenesis of LVDD and may provide a mechanism for predicting the development of LVDD in patients with DM.

\section{Abbreviations}

DM

Diabetes mellitus; LVDD:left ventricular diastolic dysfunction; HFpEF:Heart failure with preserved ejection fraction; eGFR:estimated glomerular filtration rate; LVEF:left ventricular ejection fractions; LVMI:left ventricular mass index; RWT:relative wall thickness; PWTd:end-diastolic posterior wall thickness; LVDd:end-diastolic left ventricular dimension; $\mathrm{e} \rrbracket$ velocity:peak early diastolic myocardial velocity;

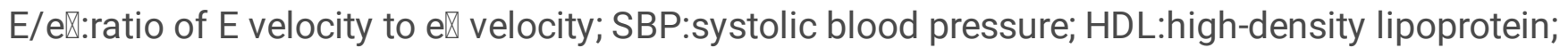
SGLT2:sodium glucose cotransporter 2; MR:mineralocorticoid receptor; $11 \beta$-HSD2:11 $\beta$-hydroxysteroid dehydrogenase type 2; T2DM:type 2 DM.

\section{Declarations}

\section{Acknowledgments}

The authors would also like to thank Ms. Chitose Matsuzaki for her assistance with clinical examinations. We thank Susan Zunino, PhD, from Edanz Group (https://en-authorservices.edanz.com/ac) for editing a draft of this manuscript.

\section{Authors' Contributions}

R.S. wrote the manuscript and researched the data. T.I. contributed to the discussion and reviewed/edited the manuscript. C.Y., M.M., N.S., and Y.O. provided advice on the interpretation of the results. R.S. and T.I. are the guarantors of this work and, as such, had full access to all of the data in the study. R.S. and T.I. also take responsibility for the integrity of the data and the accuracy of the data analysis. All named authors meet the International Committee of Medical Journal Editors (ICMJE) criteria for authorship for this manuscript, take responsibility for the integrity of the work as a whole, and have given final approval to the version to be published.

\section{Funding}


No funding or sponsorship was received for this study or publication of this article.

\section{Availability of data and materials}

The datasets generated and/or analyzed during this study are available from the corresponding author on reasonable request.

\section{Ethics approval and consent to participate}

This article is compliant with all ethical guidelines and permission was obtained to conduct this study from the Clinical Ethics Committee of Kyushu University Hospital (No. 29-33). All procedures conducted in this study were in accordance with the ethical standards of the responsible committee on human experimentation (institutional and national) and with the Helsinki Declaration of 1964, as revised in 2013. Informed consent was obtained from all patients who were included in the study.

\section{Consent for publication}

Not applicable.

\section{Competing interests}

The authors declare that they have no competing interests.

\section{References}

\section{McHugh K, DeVore AD, Wu J, Matsouaka RA, Fonarow GC, Heidenreich PA, Yancy CW, Green JB,} Altman N, Hernandez AF. Heart Failure With Preserved Ejection Fraction and Diabetes: JACC State-ofthe-Art Review. Journal of the American College of Cardiology 2019. doi:10.1016/j.jacc.2018.11.033.

2. Tanaka S, Hayashi T, Kihara Y, Takenaka K, Akaishi M, Ito H, Ishizuka N, Ohte N, Otsuji Y, Fukuda N, Mikami T, Mizushige K. Standard measurement of cardiac function indexes. Journal of Medical Ultrasonics 2006. doi:10.1007/s10396-006-0100-4.

3. Ommen SR, Nishimura RA, Appleton CP, Miller FA, Oh JK, Redfield MM, Tajik AJ. Clinical utility of Doppler echocardiography and tissue Doppler imaging in the estimation of left ventricular filling pressures: A comparative simultaneous Doppler-catheterization study. Circulation 2000. doi:10.1161/01.CIR.102.15.1788.

4. Graversen D, Vestergaard P, Stochholm K, Gravholt CH, Jørgensen JOL. Mortality in Cushing's syndrome: A systematic review and meta-analysis. European Journal of Internal Medicine 2012. doi:10.1016/j.ejim.2011.10.013.

5. Lambert JK, Goldberg L, Fayngold S, Kostadinov J, Post KD, Geer EB. Predictors of mortality and long-term outcomes in treated cushing's disease: A study of 346 patients. Journal of Clinical Endocrinology and Metabolism 2013. doi:10.1210/jc.2012-2893. 
6. Muiesan ML, Lupia M, Salvetti M, Grigoletto C, Sonino N, Boscaro M, Agabiti Rosei E, Mantero F, Fallo F. Left ventricular structural andnfunctional characteristics in Cushing's syndrome. Journal of the American College of Cardiology 2003. doi:10.1016/S0735-1097(03)00493-5.

7. Park J, de Luca A, Dutton H, Malcolm JC, Doyle MA. Cardiovascular outcomes in autonomous cortisol secretion and nonfunctioning adrenal adenoma: A systematic review. Journal of the Endocrine Society 2019. doi:10.1210/js.2019-00090.

8. Debono M, Bradburn M, Bull M, Harrison B, Ross RJ, Newell-Price J. Cortisol as a marker for increased mortality in patients with incidental adrenocortical adenomas. Journal of Clinical Endocrinology and Metabolism 2014. doi:10.1210/jc.2014-3007.

9. Inoue T, Maeda Y, Sonoda N, Sasaki S, Kabemura T, Kobayashi K, Inoguchi T. Hyperinsulinemia and sulfonylurea use are independently associated with left ventricular diastolic dysfunction in patients with type 2 diabetes mellitus with suboptimal blood glucose control. BMJ Open Diabetes Research and Care 2016. doi:10.1136/bmjdrc-2016-000223.

10. Lang RM, Bierig M, Devereux RB, Flachskampf FA, Foster E, Pellikka PA, Picard MH, Roman MJ, Seward J, Shanewise JS, Solomon SD, Spencer KT, St John Sutton M, Stewart WJ.

Recommendations for chamber quantification: A report from the American Society of

Echocardiography's guidelines and standards committee and the Chamber Quantification Writing Group, developed in conjunction with the European Association of Echocardiograph. Journal of the American Society of Echocardiography 2005. doi:10.1016/j.echo.2005.10.005.

11. Nagueh SF, Appleton CP, Gillebert TC, Marino PN, Oh JK, Smiseth OA, Waggoner AD, Flachskampf FA, Pellikka PA, Evangelisa A. Recommendations for the evaluation of left ventricular diastolic function by echocardiography. European Journal of Echocardiography 2009. doi:10.1093/ejechocard/jep007.

12. Chiodini I, Adda G, Scillitani A, Coletti F, Morelli V, di Lembo S, Epaminonda P, Masserini B, BeckPeccoz P, Orsi E, Ambrosi B, Arosio M. Cortisol secretion in patients with type 2 diabetes: Relationship with chronic complications. Diabetes Care 2007. doi:10.2337/dc06-1267.

13. Funder JW, Duval D, Meyer P. Cardiac glucocorticoid receptors: The binding of tritiated dexamethasone in rat and dog heart. Endocrinology 1973. doi:10.1210/endo-93-6-1300.

14. Sylvén C, Jansson E, Sotonyi P, Waagstein F, Barkhem T, Brönnegård M. Cardiac nuclear hormone receptor mrNA in heart failure in man. Life Sciences 1996. doi:10.1016/S0024-3205(96)00539-5.

15. Ohtani T, Mano T, Hikoso S, Sakata Y, Nishio M, Takeda Y, Otsu K, Miwa T, Masuyama T, Hori M, Yamamoto K. Cardiac steroidogenesis and glucocorticoid in the development of cardiac hypertrophy during the progression to heart failure. Journal of Hypertension 2009. doi:10.1097/HJH.0b013e328326cb04.

16. Gray GA, White Cl, Castellan RFP, McSweeney SJ, Chapman KE. Getting to the heart of intracellular glucocorticoid regeneration: 11ß-HSD1 in the myocardium. Journal of Molecular Endocrinology 2017. doi:10.1530/JME-16-0128.

17. Bauersachs J, Jaisser F, Toto R. Mineralocorticoid receptor activation and mineralocorticoid receptor antagonist treatment in cardiac and renal diseases. Hypertension 2015. 
doi:10.1161/HYPERTENSIONAHA.114.04488.

18. Funder JW. Is aldosterone bad for the heart? Trends in Endocrinology and Metabolism 2004. doi:10.1016/j.tem.2004.03.006.

19. Hayashi T, Shibata H, Kurihara I, Yokota K, Mitsuishi Y, Ohashi K, Murai-Takeda A, Jo R, Ohyama T, Sakamoto M, Tojo K, Tajima N, Utsunomiya K, Itoh H. High glucose stimulates mineralocorticoid receptor transcriptional activity through the protein kinase C $\beta$ signaling. International Heart Journal 2017. doi:10.1536/ihj.16-649.

20. Miyatake K, Okamoto M, Kinoshita N, Owa M, Nakasone I, Sakakibara H, Nimura Y. Augmentation of atrial contribution to left ventricular inflow with aging as assessed by intracardiac doppler flowmetry. The American Journal of Cardiology 1984. doi:10.1016/0002-9149(84)90035-3.

21. Owan TE, Hodge DO, Herges RM, Jacobsen SJ, Roger VL, Redfield MM. Trends in Prevalence and Outcome of Heart Failure with Preserved Ejection Fraction. New England Journal of Medicine 2006. doi:10.1056/nejmoa052256.

22. Otsuka T, Suzuki M, Yoshikawa H, Sugi K. Left ventricular diastolic dysfunction in the early stage of chronic kidney disease. Journal of Cardiology 2009. doi:10.1016/j.jjcc.2009.05.002.

23. Steiner S. Empagliflozin, cardiovascular outcomes, and mortality in type 2 diabetes. Zeitschrift fur Gefassmedizin 2016. doi:10.1056/nejmoa1504720.

24. S G, A A, J B, T P, H W, J W. Heart failure hospitalization risk associated with use of two classes of oral antidiabetic medications: an observational, real-world analysis. Cardiovascular diabetology 2017.

25. Neal B, Perkovic V, Mahaffey KW, de Zeeuw D, Fulcher G, Erondu N, Shaw W, Law G, Desai M, Matthews DR. Canagliflozin and Cardiovascular and Renal Events in Type 2 Diabetes. New England Journal of Medicine 2017. doi:10.1056/nejmoa1611925.

26. Matsutani D, Sakamoto M, Kayama Y, Takeda N, Horiuchi R, Utsunomiya K. Effect of canagliflozin on left ventricular diastolic function in patients with type 2 diabetes. Cardiovascular Diabetology 2018. doi:10.1186/s12933-018-0717-9.

\section{Supplementary Files}

This is a list of supplementary files associated with this preprint. Click to download.

- renamed4da68.docx 